\title{
O CORPO FORA, DE FRANCISCO ALVIM, COMO CONTRACENA DA MITOLOGIA DA MINEIRIDADE
}

\author{
FRANCISCO ALVIM'S O CORPO FORA \\ AS CONTRASCENE OF THE MYTHOLOGY OF THE MINEIRIDADE
}

Fernando FIORESE ${ }^{88}$

\begin{abstract}
RESUMO: Publicado pela primeira vez na edição das Poesias reunidas (1968-1988), O corpo fora, de Francisco Alvim, reúne extratos de falas que, tomadas como uma memorialística minimalista, dão a ver a contracena da história do Brasil, com privilégio de acontecimentos olvidados e personagens anônimas das Minas Gerais. Conforme o eu lírico se desdobra e se multiplica para acolher as vozes subterrâneas de múltiplos e díspares sujeitos históricos, exsurgem as entrelinhas dos discursos hegemônicos e realiza-se a revisão dos movimentos coletivos e dos fatos assentados pela história oficial. Neste sentido, a obra de Francisco Alvim contribui para a crítica e a desconstrução da "mitologia da mineiridade", urdida e conformada histórica e ideologicamente.
\end{abstract}

PALAVRAS-CHAVE: Poesia brasileira; Francisco Alvim; $O$ corpo fora; Mitologia da mineiridade; Nouvelle Histoire; Ideologia.

ABSTRACT: First published in the edition of Poesias reunidas (19681988), Francisco Alvim's O corpo fora brings together extracts from speeches that if taken as a minimalist memorial they give the contrascene of the history of Brazil, highlighting forgotten events and anonymous characters of Minas Gerais. As the poet conceals and multiplies himself to accommodate the underground voices from multiple and disparate historical subjects, arise the subtext of the hegemonic discourses and conducts the revision of collective movements and facts settled by official history. In this sense, the work of Francisco Alvim contributes to the critique and deconstruction of the "mythology of the mineiridade", historical and ideologically woven and shaped.

KEYWORDS: Brazilian poetry; Francisco Alvim; O corpo fora; Mitology of the mineiridade; Nouvelle Histoire; Ideology.

\section{Introdução}

88 Departamento de Letras, Faculdade de Letras, Universidade Federal de Juiz de Fora (UFJF), CEP 36025-150, Juiz de Fora, MG, Brasil, fernando.fiorese@acessa.com 
Quando a força ordenadora, metódica, calculista e conceitual do lógos ( $\lambda$ ó metafísico tiraniza e submete o my̆thos $(\mu \hat{0} \theta 0 \varsigma, \text { ov })^{89}$, declina o caráter múltiplo, maleável e metamórfico deste último, rasura-se a aliança do homem com os acontecimentos e a matéria do mundo, frustra-se a partilha da sabedoria e da experiência entre os indivíduos de uma comunidade, arrefece a "ingente tarefa de vivermos os my̆thoi, isto é, as palavras que dizem o concreto" (BUZZI, 1988, p. 86), fundamento da existência mítica, como assinala Arcângelo R. Buzzi em Introdução ao pensar. Não é outra coisa o que nos diz a palavra "mitologia" ( $\mu v \theta o-\lambda$ oyía, $\alpha \varsigma)-$ my̆thos + logía (lógos $+i a)^{90}$. A -logía que se pospõe a my̆thos indica o terminus technicus de submeter a voz plural e heteróclita das narrativas originárias a um tratamento totalizante e sistemático, mantendo sob controle as suas muitas variantes ou expurgando-as por completo de elementos paradoxais e contraditórios. O próprio registro escrito dos mitos, na medida em que os assenta em suporte perene e os torna disponíveis para o cotejo das suas muitas versões, pode ser entendido como sintoma da vontade de dominação da razão lógica sobre as palavras que pensam e dizem o homem, as coisas e o mundo. Sob o vigor e a vigência do lógos e da escrita, as numerosas e anônimas vozes da comunidade são domesticadas em esquemas e categorias, as narrativas orais, avessas a qualquer rigidez e flexíveis conforme as mutações da realidade, se convertem em palavra de ordem e discurso de autoridade.

Enquanto submissão do my̆thos ao lógos, a construção de toda e qualquer mitologia implica na degeneração do sentido e das funções do discurso mítico, o que permite aproximá-la do fenômeno ideológico, como descrito por Paul Ricouer em Interpretação e ideologias (1988). De forma similar ao mito, a ideologia está ligada originalmente, de acordo com o pensador francês, "à necessidade, para um grupo social, de conferir-se uma imagem de si mesmo, de representar-se, no sentido teatral do termo,

89 Acerca do embate entre my̆thos e lógos na cena originária da poiésis, ver o artigo "A palavra, seus princípios: considerações acerca do étimo de poesia" (FIORESE, 2011).

90 O substantivo my̆thos se origina dos verbos mytheomai ("falar, conversar; dizer, contar; designar, nomear; anunciar, ordenar") e mytheyo ("contar contos"). Já a palavra lógos se forma a partir de dois outros verbos, com grafia idêntica no infinitivo e sentidos distintos: légho ("dizer; declarar, anunciar; designar; ler; ordenar, mandar; falar como orador; fazer dizer") e légho ("juntar; escolher; contar, enumerar; escolher, repetir"). No Dicionário grego-português e português-grego, Isidro Pereira (1998) registra ainda um terceiro verbo légho ("deitar; deitar-se, adormecer; dormir; ficar inativo"), cujas acepções também podem relacioná-lo com a formação do substantivo lógos, como se depreende da leitura que Martin Heidegger (2001) realiza do fragmento 50 de Heráclito de Éfeso. 
de representar e encenar" (RICOUER, 1988, p. 68). No entanto, consoante o aumento da complexidade dos aspectos hierárquicos da organização social, esta função geral de integração tem que se haver com a função particular de dominação, à qual cumpre oferecer à ideologia formas de interpretar e justificar o sistema de autoridade. Assim, "é quando o papel mediador da ideologia encontra o fenômeno da dominação que o caráter de distorção e de dissimulação da ideologia passa ao primeiro plano" (RICOUER, 1988, p. 72). Por fim, acrescenta-se à ideologia a função de deformação, aquela a partir da qual Karl Marx elabora o seu conceito. Nas palavras de Ricouer,

O que Marx tenta pensar, a partir desse modelo [o modelo de inversão da religião, a ideologia por excelência], é um processo geral pelo qual a atividade real, o processo de vida real, deixa de constituir a base, para ser substituído por aquilo que os homens dizem, se imaginam, se representam. A ideologia é esse menosprezo que nos faz tomar a imagem pelo real, o reflexo pelo original (RICOUER, 1988, p. 73).

A lógica dos mitos que o termo "mitologia" manifesta parece operar em sentido análogo ao do fenômeno ideológico. Acrescentando ao papel primevo de integração dos mitos as funções de dominação e de deformação, a mitologia investe contra o caráter metamórfico das narrativas orais, ao mesmo tempo em que define o controle rigoroso ou mesmo a interrupção do fluxo contínuo das vozes que respondam ao processo da vida real. Em outras palavras, a mitologia implica na sujeição da coisa ao signo, de forma que o homem e o mundo se dobrem à ordem tranquilizadora dos conceitos e das categorias, à repetição do mesmo e à distância do real em devir.

\section{A mitologia da mineiridade}

Embora por vias teoréticas distintas, mais complexas e profusas do que as empregadas nos parágrafos anteriores, Maria A. do Nascimento Arruda alcança conclusões análogas em seu Mitologia da mineiridade: o imaginário mineiro na vida política e cultural do Brasil (ARRUDA, 1990). A partir da homologia entre mito histórico e identidade cultural, a autora elabora o rastreamento das fontes do mito da mineiridade e dos mecanismos empregados na construção da mitologia correlata, incluindo a apropriação controlada e estratégica dos muitos e diferentes discursos acerca das gentes e das paisagens de Minas Gerais. Nos modos e manobras utilizados para conferir aos mineiros uma representação identitária lógica, harmoniosa em seus termos 
adjetivos, coerente e coesa do ponto de vista histórico, realizaram-se não apenas pródigas torções interpretativas das personagens e dos acontecimentos da história mineira, mas também a rasura ou a completa eliminação da nossa memória de outros numerosos fatos, nomes e discursos, porque divergiam ou negavam uma identidade estática e concentracionária. Neste sentido, na medida da submissão dos mitos acerca de Minas à lógica e à coerência inerentes à fixação de uma identidade cultural própria dos mineiros, consignada na mitologia da mineiridade, desvela-se a natureza ideológica de tal processo:

Caberia considerar, nesse passo, se o perfil da mineiridade não tem sido retocado pelo embate político que se hospeda no interior do Estado, de onde sairia devidamente polido e pronto para ser propagado ao conjunto da sociedade. A mineiridade, no decurso da apropriação, seguiria uma trajetória autônoma vis-à-vis das suas matrizes sociais, adquirindo cunho ideológico particular, ao encontrarse deslocada do lastro social que a gerou. Configura-se, por conseguinte, um tipo de ideologia secundária, onde a capa acoberta o véu (ARRUDA, 1990, p. 15).

Os limites e os objetivos deste texto não me autorizam a apresentar uma conceituação cabal da mineiridade e uma exposição extensiva da sua mitologia, mesmo porque as linhas gerais e específicas das mesmas podem ser encontradas em numerosos títulos $^{91}$, além, obviamente, daquele citado acima. Em termos bastante abreviados, a mineiridade é "o imaginário mineiro pronto e elaborado" (ARRUDA, 1990, 87) em seus aspectos míticos, identitários e ideológicos a partir de uma apropriação que atribui significados generalizantes e irretocáveis aos fenômenos históricos, econômicos, políticos, geográficos, sociais e culturais que tiveram lugar em Minas Gerais. A construção mítica da mineiridade exigiu o amálgama e a conciliação de um sem-número de narrativas. A despeito de sua datação ou do viés encomiástico, neutro ou crítico, tais narrativas incluem desde os relatos dos viajantes estrangeiros que atravessaram o Estado ao longo do século XIX até os discursos dos cronistas, historiadores, intelectuais, memorialistas e políticos mineiros, sem descurar da substanciosa contribuição de nossos escritores e poetas, dos árcades aos modernistas. Registre-se que estes últimos, ainda quando investiam contra os traços conservadores, oligárquicos e repressivos da 91 Dentre tais títulos, destacamos: A imagem de Minas, Fernando Correia Dias (1971); Mineiridade, de Autran Dourado (1986); As Minas Gerais, de Miran de Barros Latif (1991); Voz de Minas, de Alceu de Amoroso Lima (1945); A Capitania das Minas Gerais, de Augusto de Lima Júnior; Mineiridade: ensaio de caracterização, de Sylvio Vasconcellos (1968). 
sociedade de Minas, não se eximiam de subscrever (mesmo que apenas em parte) a identidade singular do mineiro em suas fácies hegemônicas, não raro descambando para o paradoxo. A título de exemplo, referimo-nos ao volume da coleção "Brasil, terra e alma", organizado por Carlos Drummond de Andrade (1967) e dedicado a Minas Gerais, obra que per se, assim como os textos nela coligidos, exemplificam de forma cabal as relações contraditórias dos autores mineiros com a mitologia da mineiridade.

Neste sentido e além, no texto "Aí está Minas: a mineiridade”, João Guimarães Rosa refere-se às contradições do imaginário mineiro propagado em nível nacional:

Sobre o que, em seu território, ela [Minas] ajunta de tudo, os extremos, delimita, aproxima, propõe transição, une ou mistura: no clima, na flora, na fauna, nos costumes, na geografia, lá se dão encontro, concordemente, as diferentes partes do Brasil. Seu orbe é uma pequena síntese, uma encruzilhada: pois Minas Gerais é muitas. São, pelo menos, várias Minas (ROSA, 1967).

Muitas vezes apontado como escritor-monumento da mineiridade, Rosa transtorna tal imaginário e encarna os seus paradoxos, pois, ao mesmo tempo em que afiança que “o mineiro há”, termina por afirmar: “... de mim, sei, compareço como espécime negativo" (ROSA, 1967). Talvez pela origem deslocada em relação à "Zona Mineralógica" e pelo destino viageiro de médico e diplomata, o autor de Grande sertão: veredas acusa, de forma sutil, o caráter hegemônico, centralizador e reducionista da dita mineiridade:

A que via geral se divulga e mais se refere, é a Minas antiga, colonial, das comarcas mineradoras, toda na extensão da chamada Zona Mineralógica...

Essa - tradicional, pessimista talvez ainda, às vezes casmurra, ascética, reconcentrada, professa em sedições - a Minas geratriz, a do ouro, que evoca e informa, e que lhe tinge o nome; a primeira a povoar-se e a ter nacional e universal presença... (ROSA, 1967).

Mudar mitos plurais e adversativos em mitologia, submetê-los à vis lógica de uma identidade cultural única, convergente e ordenadora, exigiu o esquecimento de que, ainda segundo Rosa, "esse mineiro [da Zona Mineralógica] se estendeu de lá, porque o chão de Minas é mais, expõe maior salto de contrastes" (ROSA, 1967). Tanto que, nessas várias Minas - Zona da Mata, Sul de Minas, Triângulo, Norte etc. -, engendraram-se outros my̆thoi, consoante o movimento da história, o encontro com outras expressões humanas e culturais, as singularidades da paisagem e das relações 
políticas, sociais e econômicas estabelecidas. No entanto, mesmo que de forma camuflada ou degradada, a mitologia da mineiridade construída a partir da Zona Mineralógica persevera nos nossos ritos mais cotidianos e ainda informa o imaginário regional e nacional. Urge, pois, atender ao apelo da crítica subliminar de Rosa no sentido de desvelar e recolocar em cena os mitos produzidos nas muitas Minas - e, no mais das vezes, rasurados, pervertidos, abreviados ou simplesmente excluídos do repertório restrito e concentracionário da mitologia da mineiridade. Tal procedimento pressupõe não a ingênua e autoritária ideia de que seja possível e necessário destruir tal mitologia, mas o desejo de realizar a sua crítica e desconstrução, demonstrando o seu caráter ideológico através da proliferação de uma fartura de outros tantos mitos advindos das diversas e distintas regiões de Minas Gerais. A presença de tais outros mitos na ordem tranquilizadora do discurso que fundamenta e justifica a identidade cultural do homem mineiro reintroduzirá o paradoxo, a contradição, o desvio, a negação, o non sense que participa de todo o jogo teatral que se joga na cena da história, incluindo os bastidores do imaginário, os alçapões da ideologia e as cortinas que se abrem à traduction légendaire das realidades das várias Minas.

\section{O corpo fora, de Francisco Alvim: contracena da mitologia da mineiridade}

Não são poucos os poetas mineiros contemporâneos que revisitam, seja de forma crítica ou apenas para reafirmá-la, a questão da identidade cultural mineira, podendo-se perscrutar as suas obras à cata de elementos que permitam a construção de uma contracena discursiva em relação à mitologia da mineiridade. Dentre eles, pelos motivos que adiante restarão esclarecidos, proponho o nome de Francisco Alvim, cuja poética amalgama à tradição da lírica modernista tanto a despretensão estética e estilística quanto a crítica ao formalismo, ao engajamento político e à ideologia em geral, posturas típicas da poesia dos anos 1970 . Neste sentido, o poeta investe na dissolução da voz do eu lírico para acolher as falas de pessoas anônimas e comuns - muitas delas pertencentes às classes subalternas -, falas postas à margem do registro histórico e consideradas, por conta de sua dissonância ou contraposição, não mais que um banal desvio na sintaxe reta e férrea dos discursos ideológicos hegemônicos.

O caráter fragmentário, elíptico e minimalista da poesia de Alvim parece indicar a necessidade da leitura de cada obra como um todo textual, um fluxo de discurso (narrativo? teatral?) alimentado pela convergência de variadas vozes divergentes. Neste 
sentido, não raro os títulos dos poemas figuram como versos travestidos de títulos através das maiúsculas e do negrito, estratégia que favorece o livre trânsito e a contaminação entre os textos, bem como torna patente a inteireza escritural do livro. E tal inteireza, forjada pela travessia entre os fragmentos cumulados, acaba por desvelar uma cena dramática subliminar, fantasmática, que se abre para dar lugar às palavras dos outros. Em particular no livro $O$ corpo for $^{92}$, parece-me que se instaura uma cena propícia à manifestação das vozes das dramatis personae guardadas na memória da família mineira do autor. Além das referências explícitas em diversos poemas - "Nava" (Pedro Nava, memorialista mineiro), “Avais” (Banco Mineiro da Produção, criado ainda no período imperial), "Titia" (jornal Estado de Minas) e "Quase" (Barbacena, cidade do Campo das Vertentes), por exemplo -, as escolhas lexicais singulares, a sugestão de paisagens rurais ou de cidades interioranas e os traços psicológicos desvelados pelas vozes reunidas nesta obra atestam a sua inserção no campo plural dos mitos da mineiridade.

No artigo "Conversa dentro conversa fora", Augusto Massi não apenas atribui ao que denomina "escuta crítica de mineiro" (MASSI, 1999, p. 23) alguns dos traços marcantes da poesia de Alvim. Referindo-se especificamente a $O$ corpo fora, registra o seguinte paradoxo: “... poesia memorialística, prosa minimalista. Chico Alvim é o primeiro memorialista minimalista" (MASSI, 1999, p. 26). Tanto o paradoxo quanto o epíteto dedicado ao poeta ensejam a aproximação desta obra com um tipo específico de escrita além da memorialística, aquela escrita da história proposta no âmbito da nouvelle histoire ${ }^{93}$. Através da identificação dos traços de similaridade entre os poemas de Alvim e as teorizações e práticas da nova história em relação aos objetos, abordagens e problemas historiográficos, pretendo demonstrar como $O$ corpo fora se configura como fons et origo de uma contracena crítica em relação à mitologia da mineiridade.

Na abertura de $A$ escrita da história: novas perspectivas, embora excluindo a possibilidade de uma definição categórica, Peter Burke ressalta que "a nova história é a 92 Publicado originalmente em Poesias reunidas [1968-1988] (ALVIM, 1988, p. 7-70), O corpo fora integra também o volume Poemas [1968-2000] (ALVIM, 2004, p. 87-137). Nas citações, empregamos esta última obra.

93 Acerca da nova história, além da obra citada a seguir, ver $A$ história nova, de Jacques Le GOFF (1990), bem como os três volumes organizados por este mesmo autor em conjunto com Pierre Nora: História: novas abordagens (1976a), História: novos objetos (1976b) e História: novos problemas (1979). 
história escrita como uma reação deliberada contra o 'paradigma' tradicional" (BURKE, 1992, p. 10), propondo resumir em seis pontos o contraste entre a antiga e a nova história (Cf. BURKE, 1992, p. 10-16). De igual modo, acredito que ao menos alguns destes aspectos possam evidenciar a contraposição entre a poética alviniana e a identidade mineira hegemônica.

Em primeiro lugar, sempre segundo Burke, enquanto o paradigma tradicional propugna que "a história diz respeito essencialmente à política" (BURKE, 1992, p. 10), a história nova se interessa por toda e qualquer atividade humana, incluindo tópicos desconsiderados pelos historiadores tradicionais, tais como: a infância, a mulher, a morte, a loucura, o corpo, os odores etc. (BURKE, 1992, p. 10). No caso de Alvim, a crítica ao engajamento político e à ideologia favorece a mesma abertura temática, realizada pelo acúmulo de monólogos e diálogos que incluem chefes políticos, fazendeiros, pequeno-burgueses, funcionários públicos, trabalhadores rurais, prostitutas, donas de casa, empregadas domésticas, crianças e muitas outras personagens. Da violência doméstica às rixas políticas interioranas, da escravidão às contendas familiares, do coronelismo mineiro às brincadeiras infantis, da loucura parente ao cotidiano mais banal, dos preconceitos sociais à iniciação erótica, $O$ corpo fora agrega sem qualquer hierarquia ou juízo de valor explícito um repertório de falas que se contradizem e se complementam, se contaminam e se questionam - como demonstram os três poemas abaixo:

"OS DOIS NA COZINHA"

Entre os picumãs do teto da cozinha havia um cipó velho Que cipó é aquele meu tio?

Prendia umas cabaças com sebo de boi

Os pretos antes de ir para o eito untavam-se

Evitavam as frieiras o reumatismo (ALVIM, 2004, p. 96).

\section{“DEPOIS DA ABOLIÇÃO”}

Eu vi os filhos do Barão de Porto Novo louros olhos azuis 


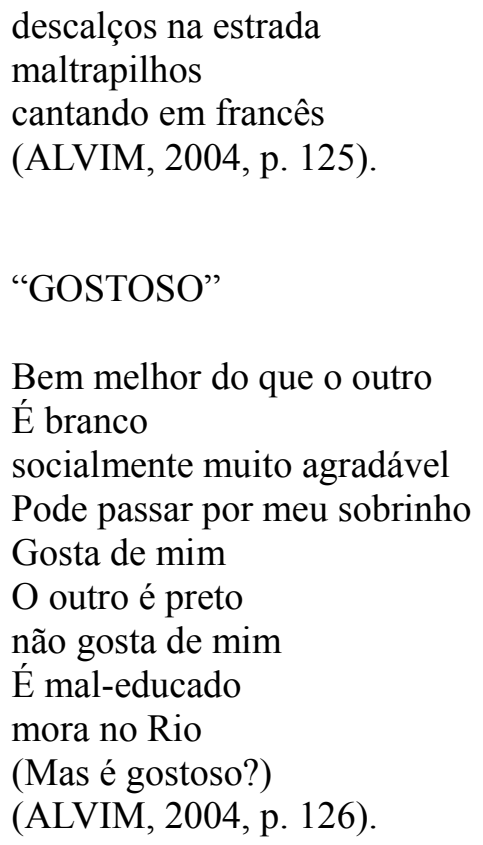

Ao tratar da questão da escravidão e seus desdobramentos, Alvim se filia não à visão de cima da história tradicional, outro dos pontos explorado por Burke (1992, p. 12-13). Distantes dos feitos dos grandes homens, as personagens a que o poeta cede a voz nos oferecem "a história vista de baixo"94, escrita com os objetivos explicitados por Jim Sharpe no artigo homônimo: “... explorar as experiências históricas daqueles homens e mulheres, cuja existência é tão frequentemente ignorada, tacitamente aceita ou mencionada apenas de passagem na principal corrente da história" (BURKE, 1992, p. 41). Neste sentido, ao debruçar-se sobre a vida cotidiana e os acontecimentos menores da gente mineira, Alvim coloca em questão, em tão poucas linhas narrativas ou dramáticas, alguns dos traços fundamentais da identidade dos mineiros, a saber: a brandura da escravidão em nossas terras, o mulatismo como sintoma da tendência democrática e como marca do caráter integrador da sociedade, o desapego quanto às aparências combinado com a altivez ${ }^{95}$.

A heteroglossia que singulariza o verso alviniano é também essencial à nova história: "Nós [os novos historiadores] nos deslocamos do ideal da Voz da História para aquele da heteroglossia, definida como "vozes variadas e opostas"” (BURKE, 1992, p. 15). Assim, na medida em que o poeta-historiador minimalista dá voz também aos 94 Acerca da história vista de baixo, ver também THOMPSON, 2001. 
homens aboletados no poder, denuncia e desconstrói, por exemplo, o caráter de insubmissão e de avessismo à autoridade que se atribui aos homens letrados de Minas, como se depreende do poema "Quase":

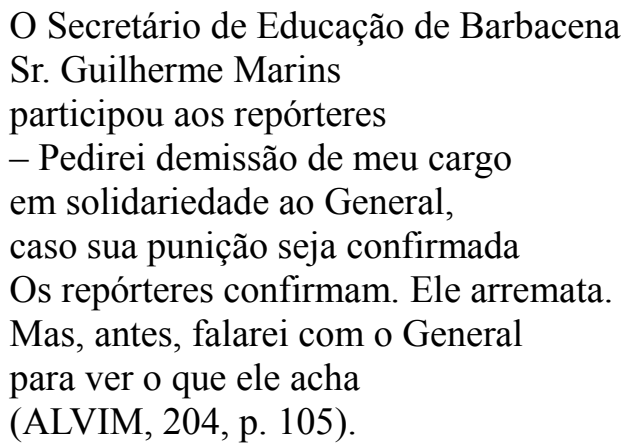

O emprego quase exclusivo da linguagem falada na poética de Alvim comunga com a primazia dos testemunhos orais no campo da história vista de baixo, ambas as estratégias permitindo escapar da falácia da objetividade pura defendida pela história tradicional (BURKE, 1992, p. 15). Trata-se de alcançar uma escrita que acolha pontos de vista vários e adversativos, o que, no caso de Alvim, significa multplicar olhos, ouvidos e línguas, significa ceder a vez e a voz - conforme a feliz expressão de Antônio Carlos Ferreira de Brito (Cacaso) no ensaio que dedica ao "Poeta dos outros" (BRITO, 1997, p. 308) - às falas e ações subterrâneas de múltiplos sujeitos históricos, de forma a deslindar as entrelinhas dos discursos hegemônicos, perturbar a ordem tranquilizadora da identidade mineira pela reintrodução de caracteres esquecidos ou eliminados e promover a revisão crítica dos movimentos coletivos e dos acontecimentos assentados pela historiografia tradicional, conforme os esquemas da mitologia da mineiridade. Apenas para acrescentar mais um exemplo aos já citados, transcrevo o poema "Briga", no qual exsurge a violência latente que o mineiro oculta e retém sob a máscara de homem sóbrio, afável, conciliador e equilibrado:

\footnotetext{
Nunca fui com a tua cara nunca escondi eu sou franco me dê tua mão quando nos conhecemos te cumprimentei assim a mão mole homem cumprimenta duro era um insulto você devia ter percebido
} 


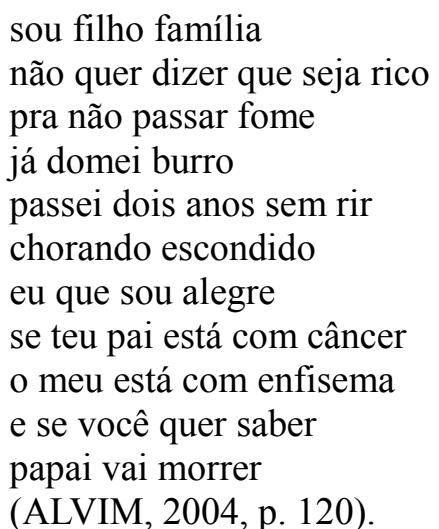

\section{Conclusão}

A considerar a proximidade entre os procedimentos escriturais da nova história e a poética de Francisco Alvim, que pretendemos ter demonstrado, ainda que de forma bastante abreviada e com demasiadas lacunas, o poeta mudado em historiador de personagens menores e acontecimentos mínimos opera em $O$ corpo fora a crítica dos paradigmas ideológicos que nortearam a construção mítica da mineiridade. Realizada a partir de uma visão microscópica e a partir de baixo, a obra nos endereça aos avessos desta mitologia, não para reafirmá-la ou reformar os seus aspectos mais nefastos, mas para dar a ver as suas lacunas, a sua violência oculta, as suas meias verdades ou falácias inteiras. Ao fazer convergir muitas das versões apócrifas, olvidadas, escamoteadas ou manipuladas dos mitos hegemônicos, Alvim não apenas amplia o repertório e dá lugar às vozes dissonantes do passado e do presente de Minas, também descarna as falas daqueles que, com meias palavras e ações intestinas, engendraram a identidade mineira com o fito de manter intacto o fóssil de nossa estrutura social, política e econômica. Portanto, não se engane o leitor, quando assim nos recebe o "Chefe da estação" no poema que abre $O$ corpo fora -

\footnotetext{
Se quiserem ficar dão muito prazer Mas se quiserem partir é hora
} (ALVIM, 2004, p. 89).

- não esperem os passageiros que decidam adentrar a contracena dessas páginas encontrar a hospitalidade mineira, mas as palavras cruas e cruéis da nossa história. 


\section{REFERÊNCIAS}

ALVIM, F. Poesias reunidas [1968-1988]. São Paulo: Duas Cidades, 1988.

. Poemas [1968-2000]. São Paulo: Cosac Naify; Rio de Janeiro: 7Letras, 2004.

ANDRADE, C. D. de. (Org.). Brasil, terra e alma. Minas Gerais. Rio de Janeiro: Ed. do Autor, 1967.

ARRUDA, M. A. do N. Mitologia da mineiridade: o imaginário mineiro na vida política e cultural do Brasil. São Paulo: Brasiliense, 1990.

BRITO, A. C. de. Não quero prosa. Campinas, SP: UNICAMP; Rio de Janeiro: UFRJ, 1997.

BURKE, P. (Org.). A escrita da história: novas perspectivas. Trad. Magda Lopes. São Paulo: UNESP, 1992.

BUZZI, A. R. Introdução ao pensar: o ser, o conhecimento, a linguagem. Petrópolis, RJ: Vozes, 1988.

DIAS, F. C. A imagem de Minas. Belo Horizonte: Imprensa Oficial, 1971.

DOURADO, A. Mineiridade. Belo Horizonte: Biblioteca Pública Luiz Bessa, 1986.

FIORESE, F. A palavra, seus princípios: considerações acerca do étimo de poesia. In: CYNTRÃO, S. H. (Org.). Poesia contemporânea: olhares e lugares. Brasília: UnB/Departamento de Teoria Literária e Literaturas, 2011. p. 87-97.

HEIDEGGER, M. Logos (Heráclito, fragmento 50). In:__. Ensaios e conferências. Trad. Emmanuel Carneiro Leão, Gilvan Fogel e Marcia Sá Cavalcante Schuback. Petrópolis, RJ: Vozes, 2001. p. 183-203.

LATIF, Miran de Barros. As Minas Gerais. Belo Horizonte: Itatiaia, 1991.

LE GOFF, J. A história nova. Trad. E. Brandão. São Paulo: Martins Fontes, 1990.

LE GOFF, NORA, P. (Org.). História: novas abordagens. Trad. Henrique Mesquita. Rio de Janeiro: Francisco Alves, 1976a.

Alves, $1976 \mathrm{~b}$.

História: novos objetos. Trad. Terezinha Marinho. Rio de Janeiro: Francisco

História: novos problemas. Trad. Theo Santiago. Rio de Janeiro: Francisco Alves, 1979.

LIMA, A. A. Voz de Minas. Rio de Janeiro: Agir, 1945.

LIMA JÚNIOR, A. de. A Capitania das Minas Gerais. Belo Horizonte/São Paulo: Itatiaia/EDUSP, 1978.

MASSI, A. Conversa dentro conversa fora. Inimigo Rumor, Rio de Janeiro, n. 6, jan./jul. 1999, p. 22-26.

PEREIRA, I. Dicionário grego-português e português-grego. Braga: Livraria Apostolado da Imprensa, 1998.

RICOUER, P. Interpretação e ideologias. Trad. Hilton Japiassu. Rio de Janeiro: Francisco Alves, 1988.

ROSA, J. G. Aí está Minas: a mineiridade. Suplemento Literário do Minas Gerais, Belo Horizonte, Imprensa Oficial, v. 2, n. 65, nov. 1967, p. 3. 
THOMPSON, E. P. A História vista de baixo. In: As peculiaridades dos ingleses e outros artigos. Campinas, SP: UNICAMP, 2001, p. 185-201.

VASCONCELLOS, S. Mineiridade: ensaio de caracterização. Belo Horizonte: Imprensa Oficial, 1968.

Artigo recebido em 28/08/2012

Aceito para publicação em 24/09/2012 